\title{
AVALIAÇÃO DO RELACIONAMENTO ENTRE DANOS MECÂNICOS E VIGOR, EM SEMENTES DE MILHO, POR MEIO DA ANÁLISE DE IMAGENS ${ }^{1}$
}

\author{
SILVIO MOURE CICERO², HODAIR LUIZ BANZATTO JUNIOR ${ }^{3}$
}

\begin{abstract}
RESUMO - A possibilidade de utilização da técnica de análise de imagens, para a determinação de danos mecânicos em sementes, é promissora; é um método de precisão, onde as sementes podem ser examinadas individualmente em imagens ampliadas e capazes de indicar, com detalhes, a área danificada, a localização e a extensão do dano. Por se tratar de método não destrutivo, as sementes em análise podem ser submetidas a testes fisiológicos e, desta forma, permitir o estabelecimento de relações entre os danos mecânicos e os prejuízos causados à qualidade. Assim, o presente trabalho teve o objetivo de estudar os efeitos dos danos mecânicos sobre o vigor de sementes de milho, utilizando a referida técnica. Cinqüenta sementes de cada um dos cultivares estudados (CO 32, AG 6690 e Attack) foram selecionadas visualmente, de tal maneira que a amostra fosse constituída por sementes íntegras e com danos mecânicos de intensidades variáveis. Em seguida, as sementes foram radiografadas, fotografadas (faces ventral e dorsal) e destinadas ao teste de frio (método do rolo de papel com terra). As plântulas normais, anormais e sementes mortas provenientes do teste de frio foram, também, fotografadas. As imagens obtidas foram disponibilizadas em computador de tal maneira que, examinadas simultaneamente na tela do monitor, pudessem ser buscadas relações de causa e efeito nas imagens anteriores e posteriores ao teste de frio. Os resultados obtidos indicam que o método estudado permite relacionar o dano mecânico com eventuais prejuízos ocasionados ao vigor das sementes de milho.
\end{abstract}

Termos para indexação: Zea mays, imagem digital, raios-X.

\section{EVALUATION OF IMAGE ANALYSIS IN DETERMINING THE RELATIONSHIP BETWEEN MECHANICAL DAMAGE AND SEED VIGOR IN MAIZE}

\begin{abstract}
Image analysis is a very promising technique to determine mechanical damage in seeds. This precise method examines seeds individually using enlarged images in which damaged areas as well as their exact location and extension can be found and examined in detail. Since this is a non-destructive method, analyzed seeds can be submitted to physiological tests to establish the relationship between mechanical damage and quality loss. The objective of the present investigation was to study the effects of mechanical damage on corn/maize seed vigor using image analysis. Fifty seeds from CO 32, AG 6690 and Attack cultivars were visually selected to form a sample of whole seeds with varying degrees of mechanical damage. The seeds were $\mathrm{x}$-rayed, photographed (ventral and dorsal sides) and submitted to a cold test. Photographs were repeated after the cold test. Images were transferred to a computer so that pre and post cold test images could be examined simultaneously on the monitor to determine the possible relationship between cause and effect. Results indicated that the method under study permits association of mechanical damage with eventual losses caused to corn/maize seed vigor.
\end{abstract}

Index terms: Zea mays L., digital image, X-rays.

\footnotetext{
${ }^{1}$ Aceito para publicação em 25.02.2003.

${ }^{2}$ Professor Titular, Departamento de Produção Vegetal, ESALQ/USP; Cx. Postal 9; 13418-900, Piracicaba, SP; bolsista do CNPq; e-mail: smcicero@carpa.ciagri.usp.br

${ }^{3}$ Técnico em Informática, Departamento de Produção Vegetal, ESALQ/USP.
}

\section{INTRODUÇÃO}

A importância de danos mecânicos em sementes de milho, sobre a emergência das plântulas em campo, é relatada por vários pesquisadores (Silveira, 1974; Leist \& Schmidt, 
1978; Feldmann, 1981; Vym \& Moes, 1988; Weller et al., 1990; Mashauri et al., 1992; Sato \& Cicero, 1992; Naplava \& Weingartman, 1994). Em contrapartida, em programas de controle de qualidade, realizados em empresas produtoras de sementes, tem sido verificado que a qualidade fisiológica, em lotes de sementes com altos índices de danos mecânicos, não tem sido influenciada negativamente. Esta contradição pode estar relacionada com imprecisões dos diagnósticos para a estimativa da taxa de danos mecânicos, inerentes aos testes de coloração com tintura iodo e verde rápido, rotineiramente utilizados. Os referidos testes, além de destrutivos, não permitem identificar com precisão os danos diretamente relacionados com as anormalidades nas plântulas ou com a morte dos embriões. Assim, todas as injúrias, independentemente da intensidade, são computadas como danos mecânicos.

Alguns pesquisadores têm tentado quantificar a extensão dos danos mecânicos próximos ao eixo embrionário; entretanto, esse procedimento visual tem se mostrado subjetivo, impreciso e ineficiente (Cicero et al., 1998). Por outro lado, Leon et al. (1986), utilizando técnicas de raios-X, pancromáticas e de infravermelho para avaliar injúrias, concluíram que a técnica de raios- $X$ foi a única capaz de detectar danos mecânicos localizados internamente nas sementes.

Reid et al. (1991), desenvolvendo sistema de visão computadorizado para detecção de danos mecânicos em grãos de milho, concluíram que o método eletrônico foi superior ao convencional. Por outro lado, a imagem digital tem sido utilizada para avaliar características externas de sementes, de bulbos e de tubérculos (Van Der Vooren et al., 1992; Van Der Vooren \& Van Der Heijden, 1993), enquanto a imagem digital de raios-X foi introduzida para avaliar as morfologias do embrião e do endosperma de sementes de Arabidopsis thaliana e de tomate (Liu et al., 1993; Bino et al., 1993; Van Der Burg et al., 1994).

Recentemente, Cicero et al. (1998), utilizando a análise de imagens para identificar os efeitos dos danos mecânicos sobre a germinação de sementes de milho, concluíram que a técnica pode ser utilizada para avaliar danos mecânicos localizados externa e internamente nas sementes, diretamente relacionados com as anormalidades de plântulas ou com a morte dos embriões; constataram que as rupturas presentes no endosperma, causando restrições na translocação de nutrientes para o eixo embrionário, ou as que ocorriam diretamente sobre o eixo embrionário, eram as que afetavam negativamente a germinação das sementes.

Dando continuidade ao trabalho realizado por Cicero et al. (1998), o presente trabalho teve o objetivo de estudar os efeitos dos danos mecânicos sobre o vigor das sementes de milho, utilizando a técnica de análise de imagens.

\section{MATERIAL E MÉTODOS}

A pesquisa foi realizada no Laboratório de Análise de Imagens e no Laboratório de Análise de Sementes, ambos pertencentes ao Departamento de Produção Vegetal da Escola Superior de Agricultura "Luiz de Queiroz", Universidade de São Paulo, em Piracicaba, SP, no período de agosto de 2001 a julho de 2002.

Cinqüienta sementes de milho de cada um dos cultivares estudados (CO 32, AG 6690 e Attack) foram selecionadas visualmente, de tal maneira que a amostra fosse constituída por sementes íntegras e com danos mecânicos de intensidades variáveis, e colocadas sobre um recipiente plástico transparente, especialmente desenvolvido para a condução da análise. As sementes foram numeradas de acordo com a posição ocupada no recipiente, de maneira que pudessem ser identificadas nas determinações posteriores. $\mathrm{O}$ recipiente foi colocado diretamente sobre um filme de raios-X (Kodak MINR 2000, tamanho de 18x24 cm), a uma distância de $35 \mathrm{~cm}$ da fonte de raios- $X$. As imagens foram obtidas com intensidade de $15 \mathrm{kV}$ e 5 minutos de exposição, utilizando-se um equipamento FAXITRON X-Ray, modelo MX-20. A revelação foi efetuada numa processadora Hope X-Ray, modelo 319 Micromax. Posteriormente, as imagens dos filmes de raios-X foram capturadas por um Scanner Umax, modelo PowerLook 1100, para ampliação e visualização em computador Pentium III (600 MHZ, memória de 256 MB, HD Ultra SCSI de 20GB e monitor de 21 ").

Paralelamente, foram obtidas imagens fotográficas externas das faces ventral e dorsal das sementes, bem como das plântulas ou das sementes mortas oriundas de cada semente após a condução do teste de vigor (relatado a seguir), por meio de uma câmera fotográfica digital Nikon, modelo D1, acoplada ao computador.

$\mathrm{O}$ vigor das sementes foi avaliado pelo teste de frio, utilizando-se o método do rolo de papel com terra. Assim, as sementes de cada cultivar, previamente numeradas (identificadas), foram distribuídas em grupos de cinco sobre duas folhas de papel-toalha "Germitest" (no terço superior do substrato, para permitir o desenvolvimento das plântulas de maneira individualizada), cobertas com uma fina camada de terra proveniente de área recentemente cultivada com milho e com mais uma folha do papel-toalha; as folhas de papel foram previamente umedecidas com quantidade de água equi- 
valente a 3,0 vezes o peso das mesmas. Em seguida, foram formados os rolos que, colocados em caixas plásticas vedadas, foram mantidos em câmara fria $\left(10^{\circ} \mathrm{C}\right)$ por sete dias. Decorrido esse prazo, os rolos foram retirados das caixas e transferidos para germinador a $25^{\circ} \mathrm{C} / 4$ dias; em seguida, as plântulas normais, anormais e as sementes mortas foram retiradas do substrato e fotografadas pela câmera fotográfica digital acoplada ao computador.

Os danos mecânicos observados nas imagens internas e externas das sementes receberam notas, de acordo com os critérios contidos na Tabela 1. As imagens e suas respectivas notas foram disponibilizadas no computador juntamente com a imagem da plântula ou da semente morta relativa àquela determinada semente. Desta maneira, todas as imagens (1: face ventral da semente, 2: face dorsal da semente, 3: morfologia interna da semente - raios-X, 4: plântula ou semente morta) puderam ser examinadas simultaneamente na tela do monitor, permitindo fazer um diagnóstico para cada semente. As notas atribuídas às imagens externas das sementes (faces ventral e dorsal) foram baseadas nos danos observados no pericarpo, embora tenham sido considerados, para

TABELA 1. Critérios utilizados para caracterizar as notas $(x, y)$ para os danos mecânicos observados no embrião e no endosperma das sementes de milho através das imagens de raios- $X$ e das faces ventral e dorsal das sementes.

\begin{tabular}{lcc}
\hline \multicolumn{1}{c}{ Dano } & Embrião (x) & Endosperma (y) \\
\hline Não observado & 1 & 1 \\
Não severo & 2 & 2 \\
Severo & 3 & 3 \\
\hline
\end{tabular}

TABELA 2. Porcentagens de sementes com danos mecânicos severos (nota 3) + não severos (nota 2), observados nas imagens externas (face ventral: na região do embrião e na região do endosperma; face dorsal: região do endosperma) e de raios-X (no embrião e no endosperma), que resultaram em plântulas anormais ou em sementes mortas nos cultivares estudados.

\begin{tabular}{lccccccc}
\hline \multirow{2}{*}{ Cultivar } & \multicolumn{3}{c}{ Imagens externas } & & \multicolumn{2}{c}{ Imagens internas } \\
\cline { 2 - 3 } \cline { 6 - 7 } & \multicolumn{2}{c}{ Face ventral } & & Face dorsal & & \multicolumn{2}{c}{ Raios-X } \\
\cline { 2 - 3 } \cline { 6 - 7 } \cline { 6 - 7 } & Embrião & Endosperma & & Endosperma & & Embrião & Endosperma \\
\hline CO 32 & 62,1 & 96,6 & & 96,6 & & 58,6 & 41,4 \\
AG 6690 & 25,0 & 80,6 & & 88,9 & & 88,9 & 80,6 \\
Attack & 58,3 & 91,7 & & 95,8 & & 83,3 & 83,3 \\
Média & 48,5 & 89,6 & & 93,8 & & 76,9 & 68,4 \\
\hline
\end{tabular}

fins de interpretação, como ocorridos nas regiões do embrião ou do endosperma.

\section{RESULTADOS E DISCUSSÃO}

A análise de imagens, por se tratar de método não destrutivo, permite comprovar, por meio de testes de germinação e de vigor, se os danos mecânicos detectados externa e internamente nas sementes apresentam efeitos sobre a qualidade fisiológica e, assim, ajudar a entender o motivo de uma determinada semente, com danos mecânicos externo e interno aparentemente importantes, originar uma plântula normal (Cicero et al., 1998).

O exame simultâneo de todas as imagens, externas (faces ventral e dorsal das sementes) e interna (raios- $\mathrm{X}$ da semente), bem como das respectivas plântulas normais, anormais ou sementes mortas observadas no teste de frio, permitiu proceder a um diagnóstico para cada caso estudado. Por outro lado, os testes de tintura iodo e verde rápido, rotineiramente utilizados para avaliar danos mecânicos em sementes de milho, permitem verificar apena s a ocorrência de injúrias externas (no pericarpo), não sendo possível avaliar se as estruturas internas foram afetadas. No presente trabalho, se fossem levados em conta apenas os exames das imagens externas (faces ventral e dorsal), as imprecisões do diagnóstico seriam, provavelmente, semelhantes aos dos dois testes citados, pois é possível, apenas, verificar danos no pericarpo. Assim, na Tabela 2 pode-se observar que menos da metade das sementes dos três cultivares estudados $(48,5 \%)$, que apresentavam na face ventral (região onde está localizado o embrião) danos que foram considerados como severos ou pouco severos, originaram plântulas anormais ou sementes mortas. Por outro lado, a maioria das sementes dos três cultivares originaram plântulas anormais ou sementes mortas, quando foram observados danos (severos ou pouco severos) na região do endosperma, tanto na face ventral, como na dorsal. Na mesma Tabela 2, verifica-se também, nas imagens de raios-X, que 76,9\% das sementes que apresentavam danos no embrião e $68,4 \%$ no endosperma originaram plântulas anormais ou sementes mortas. Tais ocorrências indicam a necessidade de se fazer um diagnóstico conjunto das imagens externas e internas das sementes.

As figuras apresentadas ilustram exemplos relativos aos três cultivares estudados. 
Na Figura 1 pode-se observar a semente 11, do cultivar Attack, na qual foram constatados danos mecânicos externos nas faces ventral (Figura 1A), com notas $1 / 2$ (dano não observado na região do embrião e dano não severo na região do endosperma) e dorsal (Figura 1B), com nota 2 (dano não severo na região do endosperma). Por outro lado, na imagem de raios-X (Figura 1C) não foram constatados danos mecânicos no embrião e no endosperma. Neste caso, a plântula normal (Figura 1D), presente após a condução do teste de frio, evidenciou a inexistência de relacionamento entre os danos (poucos severos) observados externamente na semente e a plântula originada.

Na semente 18 do cultivar CO 32 (Figura 2) foram constatados danos mecânicos externos nas faces ventral (Figura $2 \mathrm{~A}$ ), com notas $2 / 2$ (danos não severos nas regiões do em- brião e do endosperma) e dorsal (Figura 2B), com nota 2 (dano não severo na região do endosperma). A imagem de raios-X (Figura 2C), por sua vez, acusou dano severo no embrião e não severo no endosperma. A semente morta verificada no teste de frio (Figura 2D), indicou que o dano mecânico, observado na imagem de raios-X, provocou o seccionamento transversal da base da plúmula.

Na Figura 3 pode-se observar a semente 26 do cultivar AG 6690, na qual foram constatados danos mecânicos externos nas faces ventral (Figura 3A), com notas 1/2 (dano não observado na região do embrião e dano não severo na região do endosperma) e dorsal (Figura 3B), com nota 2 (dano não severo na região do endosperma). Entretanto, a imagem de raios-X (Figura 3C) acusou dano severo no embrião e não severo no endosperma, resultando uma plântula anormal (Fi-
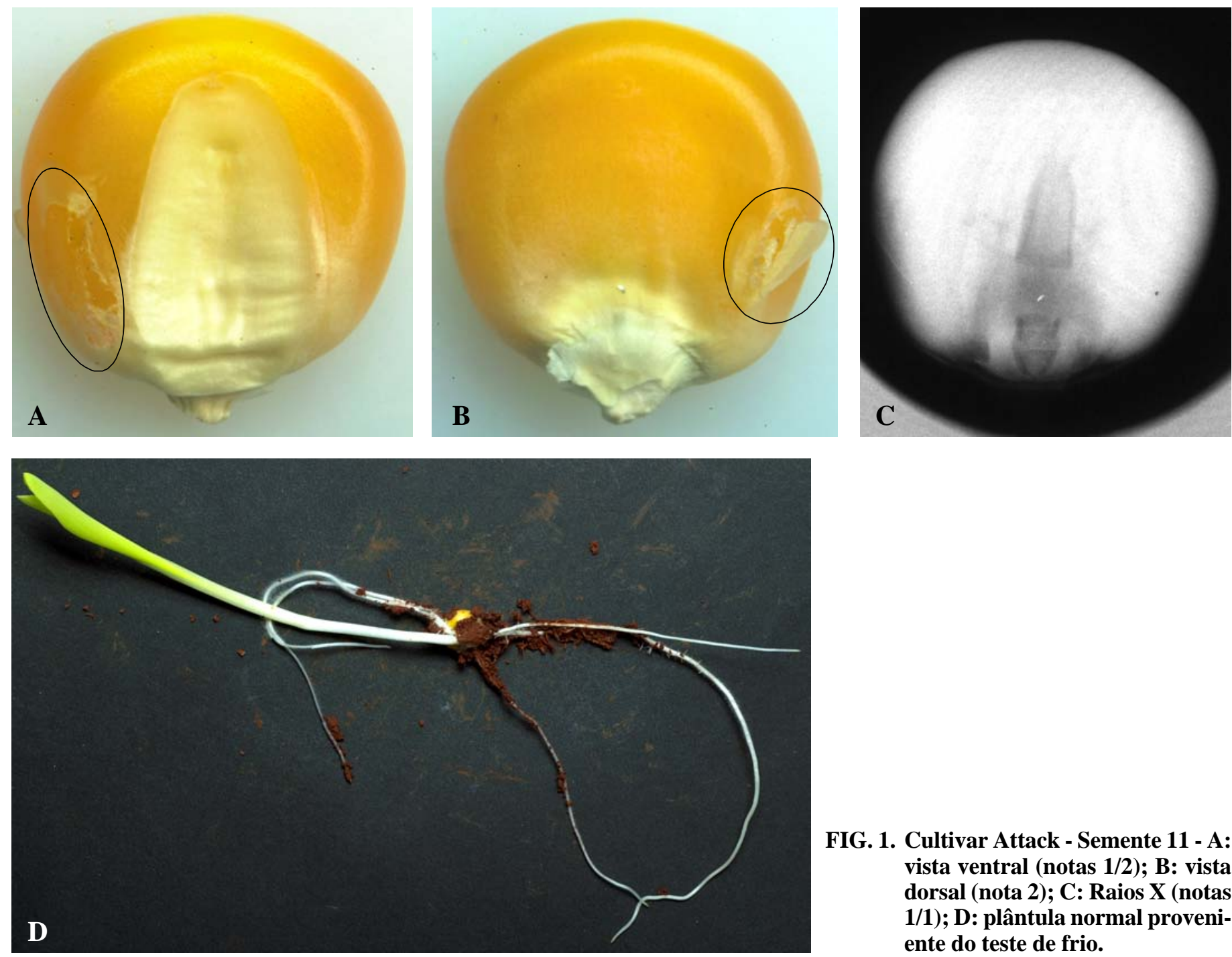

FIG. 1. Cultivar Attack - Semente 11 - A: vista ventral (notas 1/2); B: vista dorsal (nota 2); C: Raios X (notas 1/1); D: plântula normal proveniente do teste de frio. 


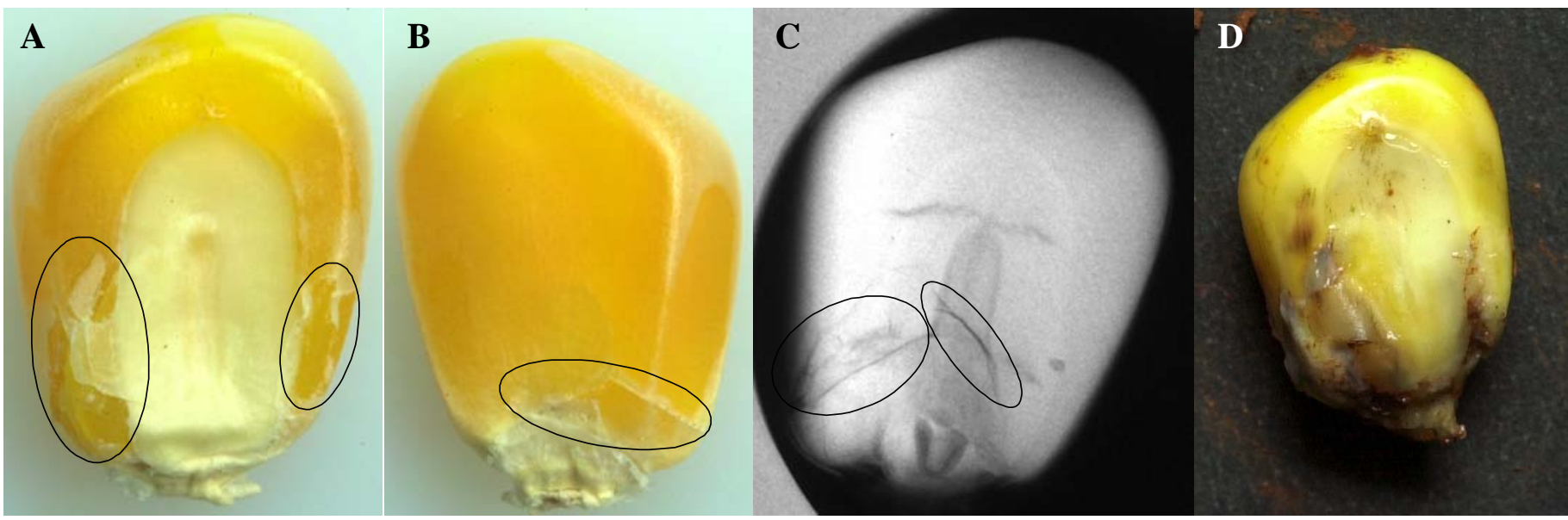

FIG. 2. Cultivar CO 32 - Semente 18 - A: vista ventral (notas 2/2); B: vista dorsal (nota 2); C: Raios-X (notas 3/2); D: semente morta proveniente do teste de frio.
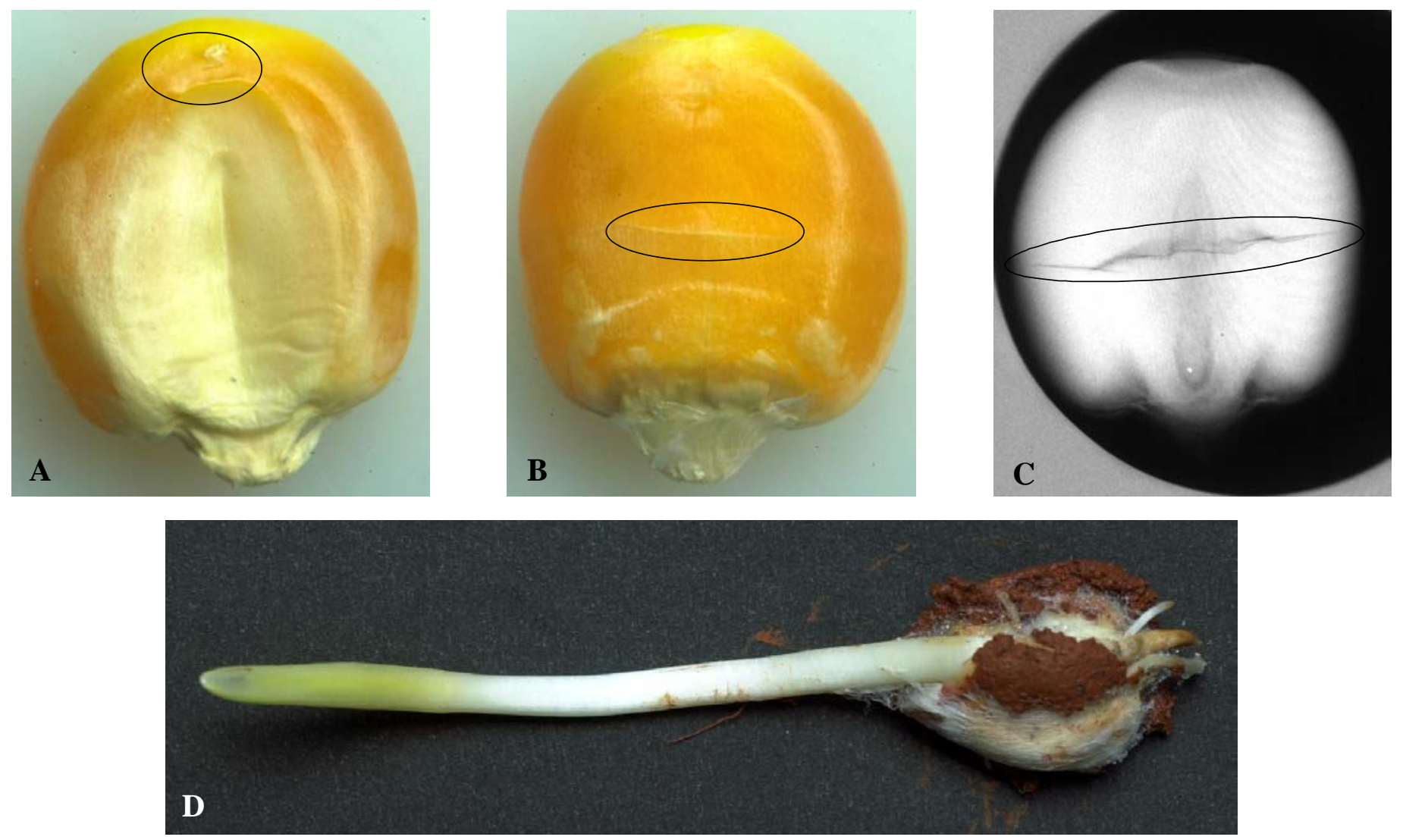

FIG. 3. Cultivar AG 6690 - Semente 26 - A: vista ventral (notas 1/2); B: vista dorsal (nota 2); C: Raios-X (notas 3/2); D: plântula anormal proveniente do teste de frio. 
gura 3D). Neste caso, o dano mecânico ocorrido na direção transversal do endosperma e do escutelo, um pouco acima do nó cotiledonar, restringiu a translocação de nutrientes do endosperma ao eixo embrionário, resultando numa plântula com plúmula precariamente desenvolvida e raízes rudimentares.

Na semente 35, do cultivar AG 6690 (Figura 4), foram constatados danos mecânicos externos nas faces ventral (Figura 4A), com notas $1 / 2$ (dano não observado na região do embrião e dano não severo na região do endosperma) e dorsal (Figura 4B), com nota 2 (dano não severo na região do endosperma). A imagem de raios-X (Figura 4C) indicou a existência de danos severo no embrião e não severo no endosperma (notas 3/2). A semente morta, obtida no teste de frio (Figura 4D), relacionou-se com o dano mecânico, observado na imagem de raios- $\mathrm{X}$, sobre o eixo embrionário.

Na Figura 5 pode-se observar a semente 13, do cultivar Attack, na qual foram constados danos mecânicos externos nas faces ventral (Figura 5A), com notas 1/2 (dano não ob- servado na região do embrião e não severo na região do endosperma) e dorsal (Figura 5B), com nota 2 (dano não severo na região do endosperma). A imagem de raios-X (Figura 5C) acusou dano severo no embrião e pouco severo no endosperma. A semente morta, obtida no teste de frio (Figura 5D), relacionou-se com o dano mecânico, observado na imagem de raios-X, sobre a plúmula.

Com base nas sementes estudadas dos três cultivares, ficou evidente que quando ocorre dano mecânico no sentido longitudinal, na região intermediária da semente, com ruptura superficial (pericarpo) sem atingir o eixo embrionário, a plântula se desenvolve normalmente. Por outro lado, ruptura profunda, afetando o eixo embrionário (Figuras 4C e 5C), resulta em plântula anormal ou em semente morta (Figuras 4D e 5D). Quando ocorre dano mecânico profundo no sentido transversal, como os detectados pelos raios-X (Figura 3C), a translocação de nutrientes do endosperma para o eixo embrionário é afetada, resultando em plântula anormal (Figura 3D) ou em semente morta.
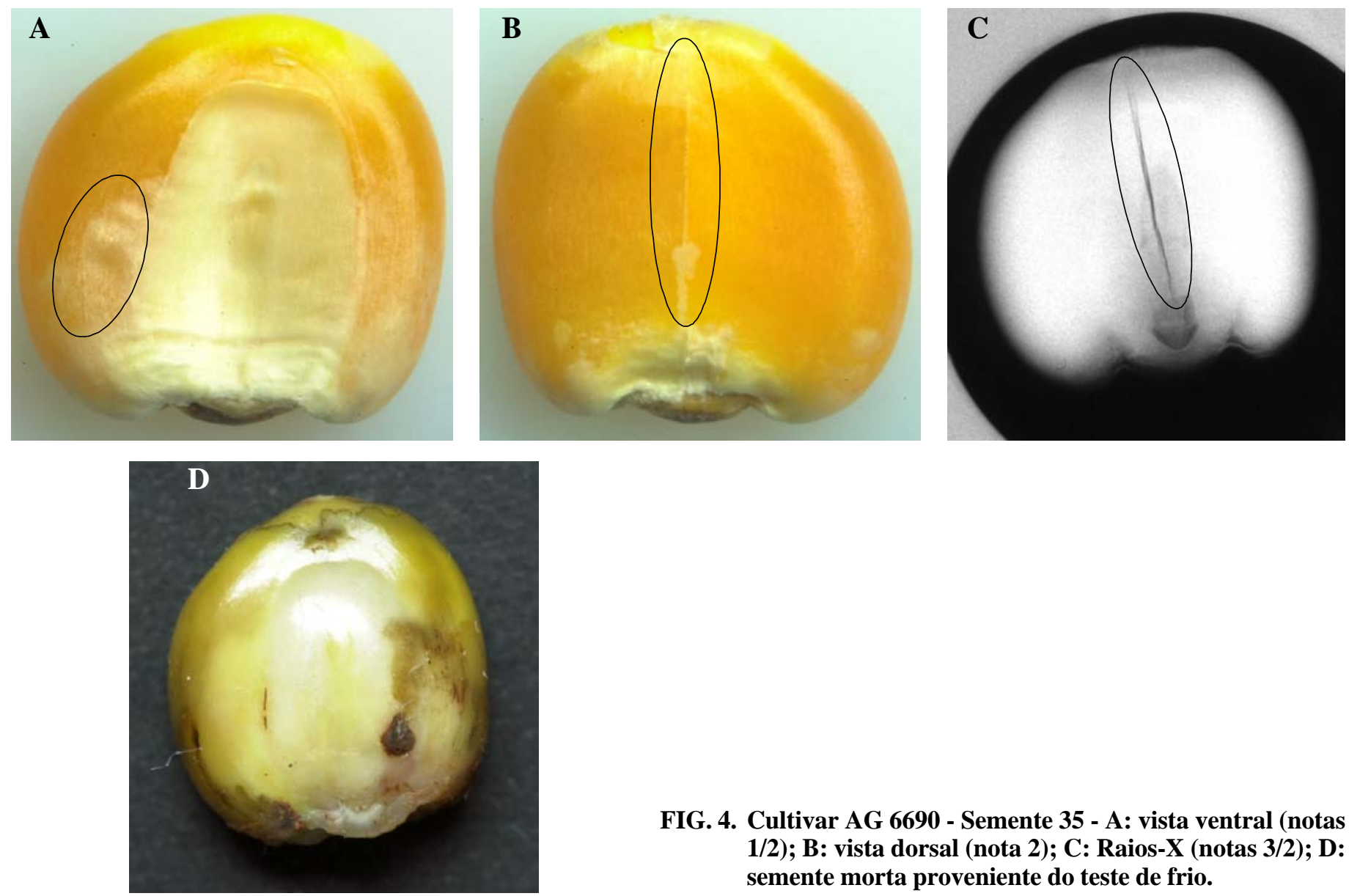

FIG. 4. Cultivar AG 6690 - Semente 35 - A: vista ventral (notas 1/2); B: vista dorsal (nota 2); C: Raios-X (notas 3/2); D: semente morta proveniente do teste de frio. 

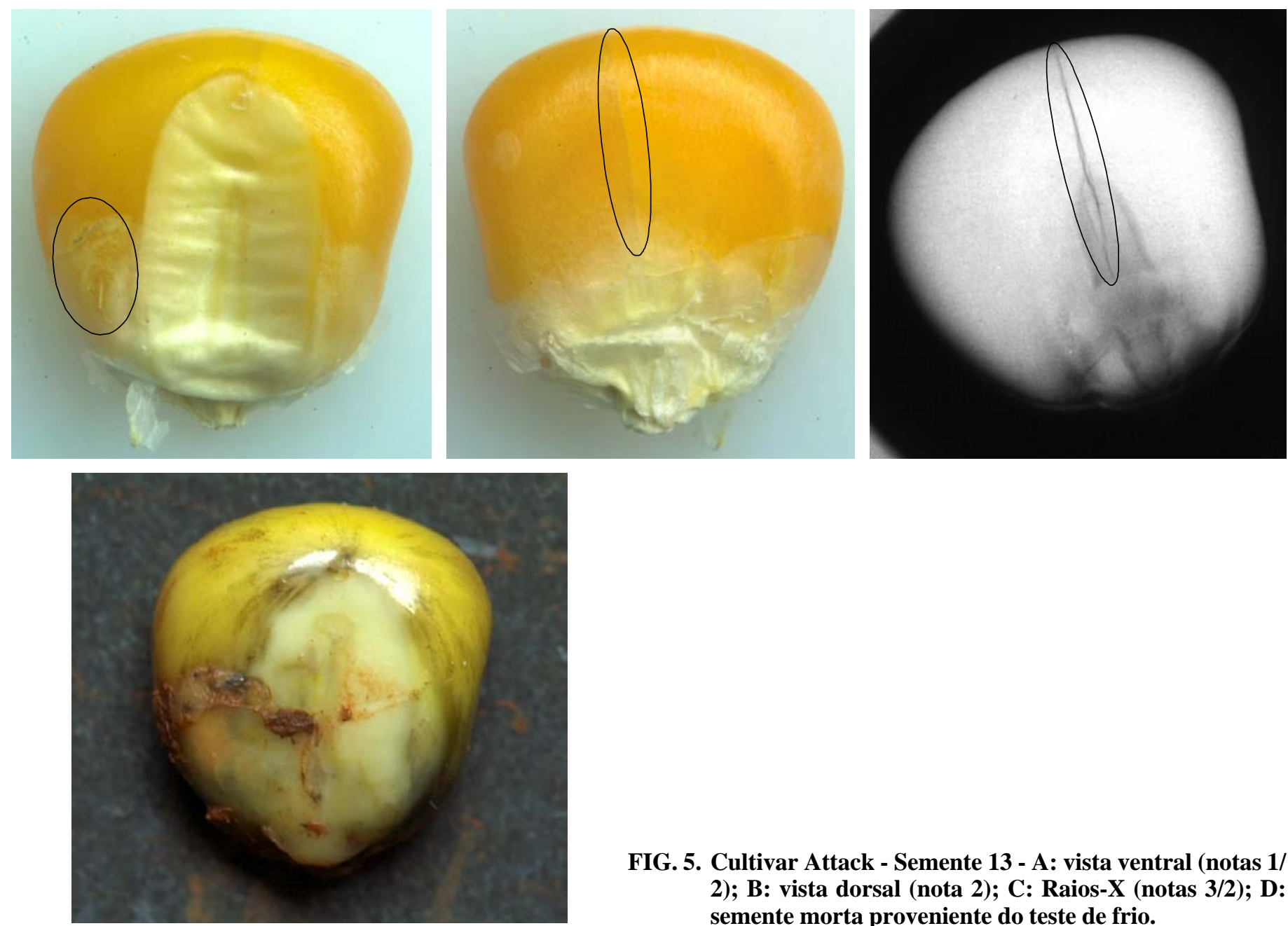

FIG. 5. Cultivar Attack - Semente 13 - A: vista ventral (notas 1/ 2); B: vista dorsal (nota 2); C: Raios-X (notas 3/2); D: semente morta proveniente do teste de frio.

Resultados semelhantes aos das Figuras 1 a 5 foram observados nas sementes dos três cultivares estudados. Da mesma forma, Cicero et al. (1998) verificaram situações semelhantes aos resultados obtidos no presente trabalho, ao estudarem a avaliação de danos mecânicos, em sementes de milho, por meio da técnica de análise de imagens; porém, os efeitos dos danos foram avaliados pelo teste de germinação.

\section{CONCLUSÕES}

Os resultados obtidos indicam que o método estudado permite relacionar o dano mecânico com eventuais prejuízos ocasionados ao vigor das sementes de milho.

\section{REFERÊNCIAS}

BINO, R.J.; AARTSE, J.W.; VAN DER BURG W.J. Non destructive X-ray of Arabidopsis embryo mutants. Seed Science Research, Wallingford, v.3, p.167-170, 1993.

CICERO, S.M. et al. Evaluation of mechanical damage in seeds of maize (Zea mays L.) by X-ray and digital imaging. Seed Science and Technology, Wallingford, v.26, p.603-612, 1998.

FELDMANN, R.O. Pesquisa em sementes de milho e sorgo no Brasil. Revista Brasileira de Sementes, Brasília, v.3, n.3, p.6774, 1981.

LEIST, G.G; SCHMIDT, B. Studies on the quality of hybrid maize seed. Dependence of seed maize quality on seed form and mechanical stress during processing. Landwirtschftliche Forschung Sonderheft, Muenster, v.35, p.488-502, 1978.

LEON, G.G. et al. Utilização de filmes radiográfico, pancromático 
e infravermelho na avaliação de danos em sementes. Revista do Centro de Ciências Rurais, Santa Maria, v.16, p.303-318, 1986.

LIU, Y. et al. X-ray studies on changes in embryo and endosperm morphology during priming and imbibition of tomato seeds. Seed Science Research, Wallingford, v.3, p.171-178, 1993.

MASHAURI, I.M.; COOLBEAR, P.; HILL, M.J. Interation between seed moisture and sheller speed during small-scale processing on the subsequent seed quality of maize (Zea mays L.). Journal of Applied Seed Production, Palmerston North, v.10, p.84-87, 1992.

NAPLAVA, V.; WEINGARTMAN, H. Stress cracks during seed corn drying. Zemedelska Technika, Praha, v.40, p.3-14, 1994.

REID, J.; KIM, C.; PAULSEN, M.R. Computer vision sensing of stress cracks in corn kernels. Transactions of the ASAE, St. Joseph, v.34, p.2235-2244, 1991.

SATO, O.; CICERO, S.M. Seleção de espigas e debulha das sementes de milho (Zea mays L.). Efeitos sobre a qualidade física e infestação por insetos. Scientia Agricola, Piracicaba, v.49, p.93-101, 1992.

SILVEIRA, J. P. Efeitos da debulha mecânica sobre a germinação, vigor e produção de cultivares de milho (Zea mays L.). 1974. 49 p. Dissertação (Mestrado) - Escola Superior de Agricultura "Luiz de Queiroz”, Universidade de São Paulo, Piracicaba, 1974.

VAN DER VOOREN, J.G.; VAN DER HEIJDEN, G.W.A.M. Measuring the size of french beans with image analysis. Plant Varieties and Seeds Gazette, Cambridge, v.6, p.47-53, 1993.

VAN DER VOOREN, J.G.; POLDER, G.; VAN DER HEIJDEN, G.W.A.M. Identification of mushroom cultivars using image analysis. Transactions of the ASAE, St. Joseph, v.35, p.347-350, 1992.

VAN DER BURG, W.J. et al. Predicting tomato seedling morphology by X-ray analysis of seeds. Journal of the American Society for Horticultural Science, Geneva, v.119, p.256-263, 1994.

VYM, T.J.; MOES, J. Breakage susceptibility of corn kernels in relation to crop management under long growing season condition. Agronomy Journal, Madison, v.80, p.915-920, 1988.

WELLER, C.L.; PAULSEN, M.R.; STEINBERG, M.P. Stress cracking and breakage susceptibility as affected by moisture content at harvest for four yellow corn hybrids. Transactions of the ASAE, St. Joseph, v.33, p.863-869, 1990. 